\title{
1 Robust clinical detection of SARS-CoV-2 variants by RT-PCR/MALDI-TOF multi-target
}

\section{2 approach}

4 Matthew M. Hernandez ${ }^{1, \#}$, Radhika Banu ${ }^{1}$, Ana S. Gonzalez-Reiche ${ }^{2}$, Adriana van de Guchte ${ }^{2}$, Zenab $5 \mathrm{Khan}^{2}$, Paras Shrestha ${ }^{1}$, Liyong $\mathrm{Cao}^{1}$, Feng Chen ${ }^{1}$, Huanzhi Shi ${ }^{1}$, Ayman Hanna ${ }^{1}$, Hala Alshammary ${ }^{3}$, 6 Shelcie Fabre ${ }^{1}$, Angela Amoako ${ }^{3}$, Ajay Obla ${ }^{2}$, Bremy Alburquerque ${ }^{2,4}$, Luz Helena Patiño ${ }^{5}$, Juan David 7 Ramírez $^{5,}$, Robert Sebra ${ }^{2,6,7,8}$, Melissa R. Gitman ${ }^{1}$, Michael D. Nowak ${ }^{1}$, Carlos Cordon-Cardo ${ }^{1}$, Ted E. 8 Schutzbank ${ }^{9}$, Viviana Simon ${ }^{1,3,10,11}$, Harm van Bakel $^{2,6}$, Emilia Mia Sordillo ${ }^{1}$, Alberto E. Paniz9 Mondolfi ${ }^{1, \#}$

11 Affiliations:

$12{ }^{1}$ Department of Pathology, Molecular, and Cell-Based Medicine, Icahn School of Medicine at Mount 13 Sinai, New York, NY 10029, USA

$14{ }^{2}$ Department of Genetics and Genomic Sciences, Icahn School of Medicine at Mount Sinai, New York, 15 NY 10029, USA

$16{ }^{3}$ Department of Microbiology, Icahn School of Medicine at Mount Sinai, New York, NY 10029, USA

$17{ }^{4}$ The Graduate School of Biomedical Sciences, Icahn School of Medicine at Mount Sinai, New York, 18 NY 10029, USA

$19{ }^{5}$ Centro de Investigaciones en Microbiología y Biotecnología-UR (CIMBIUR), Facultad de Ciencias 20 Naturales, Universidad del Rosario, Bogotá, Colombia.

$21{ }^{6}$ Icahn Institute for Data Science and Genomic Technology, Icahn School of Medicine at Mount Sinai, 22 New York, NY 10029, USA 
$23{ }^{7}$ Black Family Stem Cell Institute, Icahn School of Medicine at Mount Sinai, New York, NY 10029,

24 USA

$25{ }^{8}$ Sema4, a Mount Sinai venture, Stamford, CT 06902, USA

$26{ }^{9}$ Senior Scientific Affairs Manager, Infectious Diseases, Agena Bioscience, San Diego, CA 92121, USA

$27{ }^{10}$ Division of Infectious Diseases, Department of Medicine, Icahn School of Medicine at Mount Sinai,

28 New York, NY 10029, USA

$29{ }^{11}$ The Global Health and Emerging Pathogens Institute, Icahn School of Medicine at Mount Sinai, New

30 York, NY 10029, USA

31

32 \# Corresponding authors: alberto.paniz-mondolfi@ mountsinai.org, matthew.hernandez@mssm.edu

33 Running head: Robust detection of SARS-CoV-2 variants

34 Keywords: RT-PCR; MALDI-TOF; SARS-CoV-2; B.1.1.7; variants; diagnostic; dropout 


\section{Abstract}

36 The COVID-19 pandemic sparked rapid development of SARS-CoV-2 diagnostics. However, emerging

37 variants pose the risk for target dropout and false-negative results secondary to primer/probe binding site 38 (PBS) mismatches. The Agena MassARRAY ${ }^{\circledR}$ SARS-CoV-2 Panel combines RT-PCR and MALDI-

39 TOF mass-spectrometry to probe for five targets across $N$ and ORFlab genes, which provides a robust

40 platform to accommodate PBS mismatches in divergent viruses. Herein, we utilize a deidentified dataset

41 of 1,262 SARS-CoV-2-positive specimens from Mount Sinai Health System (New York City) from

42 December 2020 through April 2021 to evaluate target results and corresponding sequencing data.

43 Overall, the level of PBS mismatches was greater in specimens with target dropout. Of specimens with

44 N3 target dropout, 57\% harbored an A28095T substitution that is highly-specific for the alpha (B.1.1.7)

45 variant of concern. These data highlight the benefit of redundancy in target design and the potential for 46 target performance to illuminate the dynamics of circulating SARS-CoV-2 variants. 


\section{Introduction}

Molecular diagnostic assays for severe acute respiratory syndrome coronavirus-2 (SARS-CoV-

52 2), the etiologic agent of coronavirus disease 2019 (COVID-19), utilize nucleic acid amplification test

53 (NAAT) methods to assess for presence of viral nucleic acids in clinical specimens. These assays rely on

54 primers and probes targeting one or more viral gene regions including open reading frame $1 \mathrm{ab}$

$55($ ORF $1 a b)$, open reading frame $8(O R F 8)$, nucleocapsid $(N)$, spike $(S)$, and envelope $(E)^{1}$. These targets

56 have been designed primarily based on sequences from virus strains that circulated early in the

57 pandemic, including the reference genome collected from Wuhan, China in January, $2020^{2-4}$.

58 In addition to the quantity of viral nucleic acids in a clinical specimen, the diagnostic and analytic capabilities of NAATs depend on the complementarity of primers and probes to viral genome

60 sequences to reliably amplify targets of interest. As a result, binding of primers and probes can be

61 impacted by progressive accumulation of changes in the viral genomes at primer binding sites (PBSs).

62 Indeed, mismatches in PBSs - particularly the 2-3 nucleotides at the 3' end of the oligonucleotide - can

63 result in reduced binding and subsequent failure to amplify (termed "dropout" in diagnostic NAAT

64 assays) ${ }^{5-8}$. In fact, SARS-CoV-2 has diversified over the past 18 months, and mutations in the $N, S$, and

$65 E$ genes have been reported in viruses from specimens with corresponding target dropout during testing

66 on commercial NAAT-based diagnostic platforms ${ }^{9-15}$. Moreover, in silico analyses have utilized

67 publicly-available SARS-CoV-2 genome sequences to identify mutations in circulating viral variants

68 that have the potential to interfere with diagnostic targets ${ }^{1,5,16-18}$. These findings highlight the potential

69 diagnostic challenge as increasingly diverse SARS-CoV-2 lineages (e.g., B.1.1.7) continue to emerge 70 globally ${ }^{19,20}$.

71 To limit the risk of false-negative results, most NAAT assays for SARS-CoV-2 that currently

72 have emergency use authorization (EUA) from the US Food and Drug Administration (FDA) utilize two 
73 or more diagnostic targets ${ }^{21,22}$. We recently reported the analytic performance of the Agena

74 MassARRAY $^{\circledR}$ SARS-CoV-2 Panel which combines RT-PCR and matrix-assisted laser

75 desorption/ionization time-of-flight (MALDI-TOF) technologies to detect SARS-CoV-2 ${ }^{23}$. The Agena

76 MassARRAY $^{\circledR}$ platform probes for five distinct targets in the $O R F 1 a b$ and $N$ viral genes ${ }^{24}$, providing a

77 robust platform for diagnosis of SARS-CoV-2 in clinical specimens despite the emergence of virus

78 strains that have accumulated mutations that can interfere with some diagnostic targets. We evaluated

79 the pattern of target detections for SARS-CoV-2-positive specimens collected at the Mount Sinai Health

80 System (MSHS) to interrogate the impact of viral genetic variation on this diagnostic platform.

81 To do this, we compared detection of Agena diagnostic targets and genomic sequence data for

82 SARS-CoV-2-positive specimens that were deidentified and banked as part of our Pathogen

83 Surveillance Program (MSHS PSP) at the Icahn School of Medicine at Mount Sinai (ISMMS), which

84 has been previously described ${ }^{25}$. Complete viral genomes underwent phylogenetic analyses to

85 characterize emergent evolutionary lineages among the SARS-CoV-2-positive specimens at MSHS

86 (manuscript in preparation). For this analysis, we utilized a dataset comprised of 1,262 viral genomes

87 recovered from deidentified clinical specimens collected from patients seeking care at the Mount Sinai

88 Health System from December 1, 2020 through April 24, 2021. We identified PBS mismatches

89 associated with lineage-specific substitutions in SARS-CoV-2 variants of concern (VOC) that resulted in

$90 \quad$ Agena MassARRAY ${ }^{\circledR}$ platform target dropout. 


\section{Materials and Methods}

\section{Ethics statement}

This study was reviewed and approved by the Institutional Review Board of the Icahn School of

95 Medicine at Mount Sinai (HS\#13-00981).

\section{SARS-CoV-2 specimen collection and testing}

Upper respiratory tract (e.g., nasopharyngeal, anterior nares) and saliva specimens collected for

99 SARS-CoV-2 testing underwent diagnostic testing in the MSHS Clinical Microbiology Laboratory 100 (CML), which is certified under Clinical Laboratory Improvement Amendments of 1988 (CLIA), 42 101 U.S.C. $\$ 263 \mathrm{a}$ and meets requirements to perform high-complexity tests. For this study, we 102 retrospectively utilized deidentified data available for diagnostic specimens tested on the Agena 103 MassARRAY ${ }^{\circledR}$ SARS-CoV-2 Panel and MassARRAY ${ }^{\circledR}$ System (Agena, CPM384) platform during the 104 study period.

As previously described, prior to SARS-CoV-2 testing, saliva specimens underwent an initial 106 processing step involving a 15 minute incubation at $55^{\circ} \mathrm{C}$ prior to RNA extraction ${ }^{23}$. Upper respiratory 107 specimens did not undergo any pre-processing prior to testing. RNA was extracted from $300 \mu \mathrm{L}$ of each 108 specimen using the chemagic ${ }^{\mathrm{TM}}$ Viral DNA/RNA 300 Kit H96 (PerkinElmer, CMG-1033-S) on the 109 automated chemagic ${ }^{\mathrm{TM}} 360$ instrument (PerkinElmer, 2024-0020) per the manufacturer's protocol. The 110 MS2 phage RNA internal control (IC) was included in all extraction steps. The extracted RNA 111 underwent RT-PCR with iPLEX $^{\circledR}$ Pro chemistry to amplify different Agena targets, per the 112 manufacturer's protocol. After inactivation of unincorporated dNTPs by treatment with shrimp alkaline 113 phosphatase (SAP), a sequence-specific primer extension step was performed, in which a mass-modified 
114 terminator nucleotide was added to the probe, using supplied extension primers and iPLEX ${ }^{\circledR}$ Pro 115 reagents.

116 Extension products (analytes) were desalted, transferred to a SpectroCHIP ${ }^{\circledR}$ Array (silicon chip 117 with pre-spotted matrix crystal) and loaded into the MassARRAY ${ }^{\circledR}$ Analyzer (a MALDI-TOF mass 118 spectrometer). The analyte/matrix co-crystals were irradiated by a laser inducing desorption and 119 ionization, and positively charged molecules accelerated into a flight tube towards a detector. Separation 120 occurred by time-of-flight, which is proportional to molecular mass. After data processing, a spectral 121 fingerprint was generated for each analyte that characterizes the mass/charge ratio and relative intensity 122 of the molecules. Data acquired by the MassARRAY ${ }^{\circledR}$ Analyzer was processed with the MassARRAY ${ }^{\circledR}$ 123 Typer software and SARS-CoV-2 Report software. The assay detects five viral targets: three in the 124 nucleocapsid $(N)$ gene $(\mathrm{N} 1, \mathrm{~N} 2, \mathrm{~N} 3)$ and two in the ORF1ab gene (ORF1A, ORF1AB). If the IC was 125 detected, results were interpreted as positive if $\geq 2$ targets were detected or negative if $<2$ targets were 126 detected. If no IC and no targets were detected, the result was invalid and required repeat testing of the 127 specimen before reporting. If IC was detected and no targets were detected, the sample was interpreted 128 as negative.

Overall, 86,781 upper respiratory and saliva specimens underwent clinical testing in the CML at

130 MSHS, during the period from December 1, 2020 through April 24, 2021. Of those specimens, 2,062 131 tested positive for SARS-CoV-2. A subset of 1,262 specimens were deidentified, related data was 132 entered in to the MSHS PSP database, and underwent SARS-CoV-2 next-generation sequencing as 133 previously described ${ }^{25,26}$. 
medRxiv preprint doi: https://doi.org/10.1101/2021.09.09.21263348; this version posted September 16, 2021. The copyright holder for this preprint (which was not certified by peer review) is the author/funder, who has granted medRxiv a license to display the preprint in perpetuity. It is made available under a CC-BY-ND 4.0 International license .

SARS-CoV-2 viral RNA underwent reverse transcription, PCR amplification and nextgeneration sequencing followed by genome assembly and lineage assignment using a phylogeneticbased nomenclature as described by Rambaut et al. ${ }^{27}$ using the PANGOLIN tool, version 2021-04-28 28 as previously described ${ }^{25,26}$. Ultimately, this yielded 1,176 complete genomes $(\geq 95 \%$ completeness) and 86 partial genomes (<95\% completeness).

\section{Agena target sequence alignment}

Agena MassARRAY ${ }^{\circledR}$ target detection results were matched to the corresponding genome sequences. Primer and probe sequences for each Agena target were obtained from published FDA EUA documentation for the Agena MassARRAY ${ }^{\circledR}$ SARS-CoV-2 Panel (Supplemental Table S1) ${ }^{24}$. We generated reverse-complement sequences for reverse primers for all five targets and probes that are designed in the reverse orientation (e.g., N1-N3). An unaligned FASTA file including sequence data for

the clinical specimens and the Wuhan-Hu-1 reference sequence (NCBI nucleotide: NC_045512.2 (Genbank: MN908947.3)) was generated for each of the fifteen primers/probes. The Multiple Alignment using Fast Fourier Transform (MAFFT) platform ${ }^{29,30}$ which is publicly available for use online (https://mafft.cbrc.jp/alignment/server/add_fragments.html?frommanualnov6) was used to align each file. To enable inclusion of incomplete genomes that had intact regions sequenced at PBSs, we did not remove uninformative sequences (e.g., with ambiguous letters). Otherwise, the default settings were used to align all sequences to the reference genome, which generated a resulting FASTA alignment file for each primer and probe sequence. 
medRxiv preprint doi: https://doi.org/10.1101/2021.09.09.21263348; this version posted September 16, 2021. The copyright holder for this preprint (which was not certified by peer review) is the author/funder, who has granted medRxiv a license to display the preprint in perpetuity.

It is made available under a CC-BY-ND 4.0 International license .

To identify mismatches in the primer and probe regions of the viral genomes, FASTA alignment files were processed locally in a Bash environment. Custom Unix-code (https://github.com/AceM1188/SACOV_primer-probe_analyses) was used to identify mismatches at each nucleotide position within each primer and probe sequence ${ }^{31}$. A tab-delimited output file that identified mismatches by primer/probe nucleotide position across the viral genome sequences was generated for each alignment.

Note that for the viral genome sequences with stretches of Ns that corresponded with the PBS, mismatches could not be called, and these sequences were excluded from the mismatch counting for the given primer/probe. In addition, genomes with gaps that spanned the entire region of a PBS were excluded from the analyses for the given primer/probe.

Mismatches by position in PBS regions of forward/reverse primer and probe sequences were manually counted on Microsoft Excel v16.48. To account for differences in completeness of consensus genomes, the number of PBS mismatches was normalized to the number of nucleotides in the PBS of each specimen consensus sequence.

\section{Statistical analyses}

For statistical comparison of fraction of PBS with mismatches in genomes with detected targets versus those with dropout targets, normality was assessed by D'Agostino and Pearson test (GraphPad Prism 9.1.0), which indicated that all distributions were non-parametric; thus, a Mann-Whitney test (two-tailed) was performed (GraphPad). To determine if specific mismatches were associated with specific target dropout results, specimens were grouped by (1) presence or absence of the mismatch of interest (in the setting of no other mismatches) and (2) detection or dropout of the target of interest which resulted in a $2 \times 2$ contingency table which underwent association testing by Fisher's exact test. 
medRxiv preprint doi: https://doi.org/10.1101/2021.09.09.21263348; this version posted September 16, 2021. The copyright holder for this preprint (which was not certified by peer review) is the author/funder, who has granted medRxiv a license to display the preprint in perpetuity. It is made available under a CC-BY-ND 4.0 International license .

182 Display Items

183 All figures are original and were generated using the GraphPad Prism software 9.1.0, R software 184 package ggplot2, NCBI Multiple Sequence Alignment $\quad$ Viewer $\quad$ v.1.17.0 185 (https://www.ncbi.nlm.nih.gov/tools/msaviewer/), and finished in Adobe Illustrator 2021 (v.25.2.1). 186 


\section{Results}

Overall, of the 2,062 SARS-CoV-2-positive specimens, 1,274 (62\%) had all five targets detected with the remaining having one $(n=419)$ or more $(n=369)$ targets dropout. For the subset of 1,262 SARS-CoV-2-positive specimens sequenced in our study, all five diagnostic targets were detected in $943(75 \%)$, with the remaining having one $(n=227)$ or more $(n=92)$ target dropout (Supplemental

Table S2). When we calculated the target detection rate among these SARS-CoV-2-positive specimens by week, the ORF1AB target had the lowest average detection rate per week $(0.87)$ followed by the N3 target (0.88) and the N2 target (0.94) (Figure 1). Notably, the N3 detection rate declined over time with the lowest detection occurring during the last four weeks of the timeframe studied (week ending April 3 (0.75) - April 24, 2021 (0.79)). Given these observations, we used the diagnostic data and corresponding genome sequences to identify mismatches to each primer/probe utilized by the Agena MassARRAY ${ }^{\circledR}$ platform to determine the impact on target detection results.

\section{Nucleotide mismatches across diagnostic targets}

We aligned each forward primer, reverse primer, and probe sequence of the Agena

MassARRAY ${ }^{\circledR}$ SARS-CoV-2 Panel to the set of 1,262 SARS-CoV-2 genome sequences. associated with perfect complementarity ( 0 mismatches) between the genome sequence and the 207 respective target PBSs. Specifically, > 96\% of specimens with either detectable N1 or N3 targets had 208 perfect complementarity to the respective forward/reverse/probe PBS, and > 95\% of specimens with 209 detectable ORF1A or ORF1AB targets had perfect complementarity to the respective 
210 forward/reverse/probe PBS. The remaining specimens had - at most - only one mismatch to each of the

211 target PBSs. The exception to this was the N2 target, for which, more specimens with detectable N2

212 target had mismatches to N2 forward (43\%) and N2 reverse (39\%) PBSs (Figure 2B). Indeed, up to four

213 mismatches to the N2 forward and up to two mismatches to the N2 reverse PBSs were found in the

214 specimens for which the N2 target was detected.

215 When compared across target result groups, the number of mismatches was significantly higher

216 in specimens with N1, N2, N3 and ORF1A target dropout (Figure 2A-D). In addition, we found the

217 fraction of N1 probe PBS with mismatches was significantly higher in specimens with N1 target dropout

218 than in those with detectable N1 (Figure 2A).

Because the position of mismatches within PBSs affect primer binding capabilities ${ }^{1,6-8}$, we 220 characterized the mismatch frequency by position of each primer/probe. Specifically, we measured the 221 proportion of specimen genomes with a mismatch at each independent position along the full length of 222 each target's primer/probe (Figure 3, Supplemental Figure S1). From 5' to 3' direction, we found that 223 among 15 specimens with N1 target dropout, 10 harbored single mismatches to the $4^{\text {th }}-14^{\text {th }}$ basepair 224 (bp) (SARS-CoV-2 genome positions 28714 - 28704) of the 17-bp-long N1 probe PBS (Figure 3A). 225 Specifically, these mismatches reflected the following substitutions: G28714A ( $\mathrm{n}=1$ specimens), G28713A ( $n=2)$, C28709T ( $n=2)$, C28706T $(n=1)$, G28704C (n=3), G28704T (n=1).

$2303 \mathrm{bp}$ of the N2 forward primer, 336 (99\%) harbored the concurrent substitutions G28881A, G28882A, 231 and G28883C in the $N$ gene. Of the 72 specimen genomes with N2 target dropout, $34(47 \%)$ had this 232 substitution trio. Although, this polymorphism was found in 304 (26\%) of the 1,163 specimen genomes 
233 with $\mathrm{N} 2$ target detection, statistically, this represents a significant association of the GGG-to-AAC 234 substitution with N2 target dropout (Fisher's exact, $\mathrm{p}=0.0002$ ).

In addition, specimens that harbor mismatches to the 5' end of the $\mathrm{N} 2$ reverse primer are the result of the C28977T or G28975A substitutions. However, of 466 specimens that harbor either

237 substitution, only 1 had both suggesting these substitutions occur independently of one another. When 238 grouped by N2 target detection result, neither substitution was significantly associated with N2 target 239 dropout (Fisher's exact, $\mathrm{p} \geq 0.1351$ ).

Interestingly, we found that of the 110 specimen genomes with N3 target dropout, $63(57 \%)$ had 241 a mismatch at the penultimate nucleotide towards the 3' end in the 20-bp-long N3 forward primer 242 (Figure 3C). All mismatches at this position are the result of a specific adenine-to-thymine substitution 243 in ORF8 (A28095T) of the SARS-CoV-2 genome. Of the 1,102 genomes with detected N3 target, only 244 two harbored this mismatch; overall, this represents a statistically significant association of this 245 positional mismatch with N3 target dropout (Fisher's exact, $\mathrm{p}<0.0001$ ).

We also assessed whether the association of these mismatches with target dropout is maintained

247 when the quantity of virus in the specimen is controlled. Although the Agena platform yields a 248 qualitative diagnostic result, we have demonstrated previously that the number of detected targets is 249 proportional to the quantity of virus in a given specimen ${ }^{23}$. When we limit our dataset only to specimens 250 for which all other (e.g., non-N3) targets are detected, the association of the A28095T substitution with 251 N3 target dropout remains statistically significant (Fisher's exact, $p<0.0001$ ), indicating that N3 target 252 dropout due to the A28095T substitution is independent of differences in virus concentration. 
In order to assess whether target dropout was due to lineage-specific variation, we examined the phylogenetic lineages of genomes harboring distinct substitutions in our dataset. Among the 34 specimens with the concurrent GGG-to-AAC tri-nucleotide substitution and N2 target dropout, the earliest was from December 29, 2020 (PV24926) which belonged to the B.1.1.434 lineage. This polymorphism did not demonstrate bias to any one lineage in specimens that yielded N2 target dropout as it was found in specimens that mapped to 15 different lineages including B.1.1.7 (alpha, $\mathrm{n}=11$ ), B.1.1.434 $(n=6)$, and B.1.1 $(n=4)$ lineages.

We next examined the phylogenetic lineage of genomes harboring the A28095T substitution in our dataset to assess whether N3 target dropout was due to lineage-specific variation. We found that the earliest specimen with this substitution was from January 8, 2021 (specimen PV25263) and belonged to the B.1.1.7 lineage. Indeed, the substitution appeared in a subset of genomes of the B.1.1.7 lineage. substitution while the remaining maintained the adenine at the position (Figure 4). Ninety-seven percent (63/65) of the B.1.1.7 specimens with the A20895T substitution demonstrated N3 target dropout. Furthermore, the converse was also true as almost all B.1.1.7 specimens with N3 target dropout (63/64 (98\%)) had the A28095T substitution (Figure 4A).

Among the other 45 specimens with N3 target dropout, 10 harbored mismatches in the N3 PBS

274 assigned. The other 9 genomes represented B.1.2 $(n=3)$, B.1.36.18 $(n=1)$, B.1.427 $(n=2)$, B.1.575 $(n$ $275=2)$, and B.1.621 $(\mathrm{n}=1)$ lineages. Among these non-B.1.1.7 genomes, three mismatches were identified 276 at the $1^{\text {st }}(\mathrm{G} 28077 \mathrm{~T} ; \mathrm{n}=1), 11^{\text {th }}(\mathrm{C} 28087 \mathrm{~T} ; \mathrm{n}=3)$ and $17^{\text {th }}(\mathrm{C} 28093 \mathrm{~T} ; \mathrm{n}=5)$ bp of the N3 forward PBS 277 which were encoded by viruses from multiple lineages. Of note, these non-B.1.1.7 genomes did not have 
medRxiv preprint doi: https://doi.org/10.1101/2021.09.09.21263348; this version posted September 16, 2021. The copyright holder for this preprint (which was not certified by peer review) is the author/funder, who has granted medRxiv a license to display the preprint in perpetuity. It is made available under a CC-BY-ND 4.0 International license .

278 any other mismatches in the N3 reverse or probe PBS. Furthermore, the two mismatches closest to the 3'

279 end of the N3 forward primer - C28087T and C28093T - were significantly associated with N3 target

280 dropout (Fisher's exact, $\mathrm{p}=0.0407$ and $\mathrm{p}<0.0001$, respectively), but the mismatch at the first position

281 was not significantly associated with N3 target dropout (Fisher's exact, $\mathrm{p}=0.0914$ ). 


\section{Discussion}

Molecular assays for the diagnosis of COVID-19 developed early in the pandemic utilize primers and probes based on conserved regions in the then-available SARS-CoV-2 genome sequences. Now, more than 18 months later, circulating SARS-CoV-2 variants have accumulated numerous nucleotide substitutions in response to evolutionary pressures. These genomic variations can be associated with increased infectivity, transmissibility, and disease pathogenesis ${ }^{32-36}$, warranting accurate and quick surveillance efforts. However, genome variation can also be a challenge for detection of these variants of interest (VOIs) or VOCs if mismatches to PBSs in diagnostic targets are present. A number of studies have described substitutions in the ORFlab, $S, E$, and $N$ genes that may interfere with specific RT-PCR targets ${ }^{1,5,9,11,12,14-16,18}$, but these studies have inherent limitations. Several are in silico analyses that do not reflect diagnostic performance in the clinical setting ${ }^{1,5,16,18}$, whereas others do not definitively demonstrate target dropout due to substitutions as they utilize platforms for which primer/probe sequence information is not publicly available ${ }^{9,11,14,15}$. In addition, the later studies are based on assays that interrogate up to 3 diagnostic targets, and are limited by the number and diversity of viral sequences surveyed over finite timeframes, some prior to the emergence and expansion of VOCs.

In the current study, we describe a robust evaluation of the impact of PBS mismatches on Agena MassARRAY ${ }^{\circledR}$ SARS-CoV-2 Panel target results for over 1,200 specimens over a five-month time period that corresponds with the rapid emergence of viral VOIs/VOCs (December 2020 through April 2021). This large dataset enabled direct correlation of detection of each of five different Agena diagnostic viral targets with genomic sequence data

Additionally, by using publicly available primer/probe sequences to map lineage-specific substitutions, we were able to further evaluate the impact of mismatches on target results and to demonstrate an association between variation in SARS-CoV-2 PBSs and target dropout. Our analysis 
revealed that several mutations result in N1 and N3 target dropout. Interestingly, although specimens from other lineages harbor mismatches in the N3 target region, we identified a distinct association between the B.1.1.7-associated A28095T substitution and dropout of the N3 diagnostic target on the Agena MassARRAY ${ }^{\circledR}$ SARS-CoV-2 Panel. This finding represents the first description of a lineagespecific substitution that introduces a mismatch to a publicly available primer sequence and yields

311 diagnostic target dropout. This underscores the utility of publicly available sequences to further monitor their diagnostic ability as SARS-CoV-2 continues to evolve and new lineages emerge.

The B.1.1.7 lineage (alpha) has been designated as a variant of concern by the World Health

314 Organization and the US Centers for Diseases Control and Prevention due to its increased

315 transmissibility ${ }^{20,33-35,37}$. This lineage was first reported in > 1,100 cases in the United Kingdom (UK)

316 on December $14,2020^{38}$, but it has been estimated to have emerged in September $2020^{20,35}$. Since then,

317 the B.1.1.7 lineage spread rapidly, comprising > 90\% of new SARS-CoV-2 infections in the UK by 318 March $2021^{35}$. This lineage also spread globally, including in the US ${ }^{39,40}$, where recent epidemiological 319 reports indicate B.1.1.7 variants caused $>60 \%$ of the new infections as of May $6,2021^{41}$.

These characteristics further underscore the urgency to update and continually develop robust screening modalities to capture VOCs like B.1.1.7. Sequencing of these variants remains the 'gold standard' of surveillance, but not all diagnostic laboratories have the infrastructure or capacity to readily utilize this technology. $S$ gene target failure (SGTF) on commercial RT-PCR platforms has been proposed as a screening alternative to detect the $\mathrm{S}$ protein deletion $\mathrm{H} 69-\mathrm{V} 70(\Delta \mathrm{H} 69 / \Delta \mathrm{V} 70)^{14,15,42,43}$ which is found in B.1.1.7 and, to a lesser extent, in other circulating lineages (e.g., B.1.525, B.1.620 (NextStrain, build June 23, 2021)) ${ }^{15}$.

328 specimens of interest for whole genome sequencing and variant classification. Notably detection of the 
B.1.1.7 variant containing the A28095T substitution is associated with the Agena N3 target dropout.

330 This substitution is characteristic of $50 \%$ of the circulating B.1.1.7 specimens in our dataset and reflects

331 a unique snapshot of genomic variation occurring within the circulating B.1.1.7 variants in New York

332 City. The A28095T substitution introduces a stop codon in the $O R F 8$ gene producing a truncated version

333 with potential functional changes in encoded protein (K68stop). Among a dataset of $>2$ million publicly

334 available viral genomes from global surveillance efforts (GISAID, June 23, 2021), 309,050 genomes

335 harbor this substitution. Nearly all (99.9\%) of these A28095T-genomes belong to the B.1.1.7 lineage

336 which, in turn, represent a sub-population (33.9\%) of all B.1.1.7 genomes. Therefore, continued

337 diagnostic surveillance of the Agena N3 target dropout and subsequent genomic surveillance can be

338 exploited to monitor the spread of the B.1.1.7 variant as well as other VOCs. Indeed, based on publicly

339 available genomes, other VOCs harbor substitutions that result in mismatches to Agena target PBSs. For

340 example, $73 \%$ of delta (B.1.617.2) variant genomes have the non-synonymous substitution, G28916T in

341 the $N$ gene (amino acid change, $\mathrm{G} 215 \mathrm{C}$ ) which introduces a mismatch to the terminal bp of the $\mathrm{N} 2$ probe

342 (GISAID, June 23, 2021). Given its position in the probe, this mismatch likely impacts N2 target

343 performance. This warrants further study, particularly as the B.1.617.2 VOC continues to expand

344 globally ${ }^{44-46}$ since its parent lineage was first identified in India in October $2020{ }^{47-49}$.

An important potential limitation of our study is that target performance can be affected when

346 the quantity of viral nucleic acids in diagnostic specimens is at or near the assay limit of detection, and

347 that the limit of detection varies for different targets. We have demonstrated previously that Agena

348 MassARRAY ${ }^{\circledR}$ target detection is proportional to quantity of viral nucleic acids ${ }^{23}$. Thus, detection of

349 other targets can be used as a control to evaluate the performance of an individual target, such as N3

350 target dropout in the setting of the B.1.1.7 A28095T variant. In addition, we have also identified other 351 mutations in this study that are associated with N1 and N3 target dropout. However, unlike the B.1.1.7 
352 A28095T/A genomes in our dataset, these are fewer in number and further comprehensive evaluation is 353 needed to determine the definitive impact on target performance.

354 Assay platforms that incorporate testing of multiple targets within the virus genome are more 355 likely to retain diagnostic sensitivity as SARS-CoV-2 continues to diversify and new variants emerge.

356 Diagnostic target performance patterns on these redundant platforms have the potential to accommodate 357 unfolding genomic variation in a timely manner, and highlight the potential of diagnostic results to serve 358 as a robust system for detection of these emergent SARS-CoV-2 variants. These qualities demonstrate 359 the importance of these platforms to capture the evolutionary consequences of the ongoing pandemic to 360 inform public health and infection prevention measures. 
medRxiv preprint doi: https://doi.org/10.1101/2021.09.09.21263348; this version posted September 16, 2021. The copyright holder for this preprint (which was not certified by peer review) is the author/funder, who has granted medRxiv a license to display the preprint in perpetuity. It is made available under a CC-BY-ND 4.0 International license.

\section{Code availability}

362 To generate genome sequences, sequencing data were analyzed using a custom reference-based

363 (MN908947.3) pipeline, https://github.com/mjsull/COVID_pipe ${ }^{50}$. To analyze mismatches to diagnostic 364 target PBSs, genome sequences were analyzed using a custom Unix-code

365 https://github.com/AceM1188/SACOV_primer-probe_analyses ${ }^{31}$.

\section{Data availability}

368 SARS-CoV-2 sequencing read data for all study genomes were deposited in GISAID [www.gisaid.org] 369 (accessions pending). 


\section{References}

372 1. Wang R, Hozumi Y, Yin C, Wei G-W. Mutations on COVID-19 diagnostic targets. Genomics, $373 \quad 2020,112: 5204-13$

374 2. Chan JF-W, Yip CC-Y, To KK-W, Tang TH-C, Wong SC-Y, Leung K-H, Fung AY-F, Ng AC-K, Zou Z, Tsoi H-W, Choi GK-Y, Tam AR, Cheng VC-C, Chan K-H, Tsang OT-Y, Yuen K-Y. Improved molecular diagnosis of COVID-19 by the novel, highly sensitive and specific COVID-

3. Wu F, Zhao S, Yu B, Chen Y-M, Wang W, Song Z-G, Hu Y, Tao Z-W, Tian J-H, Pei Y-Y, Yuan 19-RdRp/Hel real-time reverse transcription-PCR assay validated in vitro and with clinical

4. Udugama B, Kadhiresan P, Kozlowski HN, Malekjahani A, Osborne M, Li VYC, Chen H, M-L, Zhang Y-L, Dai F-H, Liu Y, Wang Q-M, Zheng J-J, Xu L, Holmes EC, Zhang Y-Z. A new coronavirus associated with human respiratory disease in China. Nature, 2020, 579:265-9 specimens. J Clin Microbiol, 2020, 58 Mubareka S, Gubbay JB, Chan WCW. Diagnosing COVID-19: The disease and tools for detection. ACS Nano, 2020, 14:3822-35

5. Gand M, Vanneste K, Thomas I, Van Gucht S, Capron A, Herman P, Roosens NHC, De Keersmaecker SCJ. Deepening of In Silico Evaluation of SARS-CoV-2 Detection RT-qPCR Assays in the Context of New Variants. Genes , 2021, 12

6. Kwok S, Kellogg DE, McKinney N, Spasic D, Goda L, Levenson C, Sninsky JJ. Effects of primertemplate mismatches on the polymerase chain reaction: human immunodeficiency virus type 1 model studies. Nucleic Acids Res, 1990, 18:999-1005

7. Lefever S, Pattyn F, Hellemans J, Vandesompele J. Single-nucleotide polymorphisms and other mismatches reduce performance of quantitative PCR assays. Clin Chem, 2013, 59:1470-80 
393 8. Whiley DM, Sloots TP. Sequence variation in primer targets affects the accuracy of viral 394 quantitative PCR. J Clin Virol, 2005, 34:104-7

395 9. Tahan S, Parikh BA, Droit L, Wallace MA, Burnham CA, Wang D. SARS-CoV-2 E gene variant 396 alters analytical sensitivity characteristics of viral detection using a commercial RT-PCR assay. J 397 Clin Microbiol, 2021. https://doi.org/10.1128/JCM.00075-21

10. Vanaerschot M, Mann SA, Webber JT, Kamm J, Bell SM, Bell J, Hong SN, Nguyen MP, Chan LY, Bhatt KD, Tan M, Detweiler AM, Espinosa A, Wu W, Batson J, Dynerman D, Wadford DA, Puschnik AS, Neff N, Ahyong V, Miller S, Ayscue P, Tato CM, Paul S, Kistler AL, DeRisi JL, Crawford ED. Identification of a polymorphism in the $\mathrm{N}$ gene of SARS-CoV-2 that adversely impacts detection by reverse transcription-PCR. J Clin Microbiol, 2020, 59:e02369-20

11. Artesi M, Bontems S, Göbbels P, Franckh M, Maes P, Boreux R, Meex C, Melin P, Hayette M-P, Bours V, Durkin K. A Recurrent Mutation at Position 26340 of SARS-CoV-2 Is Associated with

12. Vogels CBF, Brito AF, Wyllie AL, Fauver JR, Ott IM, Kalinich CC, Petrone ME, CasanovasFailure of the E Gene Quantitative Reverse Transcription-PCR Utilized in a Commercial DualTarget Diagnostic Assay. J Clin Microbiol, 2020, 58 Massana A, Catherine Muenker M, Moore AJ, Klein J, Lu P, Lu-Culligan A, Jiang X, Kim DJ, 
medRxiv preprint doi: https://doi.org/10.1101/2021.09.09.21263348; this version posted September 16, 2021. The copyright holder for this preprint (which was not certified by peer review) is the author/funder, who has granted medRxiv a license to display the preprint in perpetuity.

It is made available under a CC-BY-ND 4.0 International license .

415 14. Brown KA, Gubbay J, Hopkins J, Patel S, Buchan SA, Daneman N, Goneau LW. S-Gene Target 416 Failure as a Marker of Variant B.1.1.7 Among SARS-CoV-2 Isolates in the Greater Toronto Area, 417 December 2020 to March 2021. JAMA, 2021, 325:2115-6

418 15. Bal A, Destras G, Gaymard A, Stefic K, Marlet J, Eymieux S, Regue H, Semanas Q, d'Aubarede C, 419 Billaud G, Laurent F, Gonzalez C, Mekki Y, Valette M, Bouscambert M, Gaudy-Graffin C, Lina B, 420 Morfin F, Josset L, COVID-Diagnosis HCL Study Group. Two-step strategy for the identification 421 of SARS-CoV-2 variant of concern 202012/01 and other variants with spike deletion H69-V70, 422 France, August to December 2020. Euro Surveill, 2021, 26

423 16. Gand M, Vanneste K, Thomas I, Van Gucht S, Capron A, Herman P, Roosens NHC, De 424 Keersmaecker SCJ. Use of Whole Genome Sequencing Data for a First in Silico Specificity 425 Evaluation of the RT-qPCR Assays Used for SARS-CoV-2 Detection. Int J Mol Sci, 2020,21 426 17. Tahamtan A, Ardebili A. Real-time RT-PCR in COVID-19 detection: issues affecting the results. 427 Expert Rev Mol Diagn, 2020, 20:453-4

428 18. Khan KA, Cheung P. Presence of mismatches between diagnostic PCR assays and coronavirus 429 SARS-CoV-2 genome. R Soc Open Sci, 2020, 7:200636

430 19. Mercer TR, Salit M. Testing at scale during the COVID-19 pandemic. Nat Rev Genet, 2021. $431 \quad$ https://doi.org/10.1038/s41576-021-00360-w

432 20. Preliminary genomic characterisation of an emergent SARS-CoV-2 lineage in the UK defined by a 433 novel set of spike mutations, 2020. https://virological.org/t/preliminary-genomic-characterisation434 of-an-emergent-sars-cov-2-lineage-in-the-uk-defined-by-a-novel-set-of-spike-mutations/563. $435 \quad$ (accessed May 21, 2021)

436 21. In Vitro Diagnostics EUAs. US Food and Drug Administration, Febraury 17, 2021. 437 https://www.fda.gov/medical-devices/coronavirus-disease-2019-covid-19-emergency-use- 
medRxiv preprint doi: https://doi.org/10.1101/2021.09.09.21263348; this version posted September 16, 2021. The copyright holder for this preprint (which was not certified by peer review) is the author/funder, who has granted medRxiv a license to display the preprint in perpetuity.

It is made available under a CC-BY-ND 4.0 International license .

authorizations-medical-devices/vitro-diagnostics-euas\#individual-molecular. (accessed February 21, 2021)

22. Rybicka M, Miłosz E, Bielawski KP. Superiority of MALDI-TOF mass spectrometry over realtime PCR for SARS-CoV-2 RNA detection. Viruses, 2021, 13

23. Hernandez MM, Banu R, Shrestha P, Patel A, Chen F, Cao L, Fabre S, Tan J, Lopez H, Chiu N, Shifrin B, Zapolskaya I, Flores V, Lee PY, Castañeda S, Ramírez JD, Jhang J, Osorio G, Gitman MR, Nowak MD, Reich DL, Cordon-Cardo C, Sordillo EM, Paniz-Mondolfi AE. RTPCR/MALDI-TOF mass spectrometry-based detection of SARS-CoV-2 in saliva specimens. J Med Virol, 2021. https://doi.org/10.1002/jmv.27069

24. Agena Bioscience, Inc. MassARRAY@ SARS-CoV-2 Panel Instructions for Use. 2021

25. Gonzalez-Reiche AS, Hernandez MM, Sullivan MJ, Ciferri B, Alshammary H, Obla A, Fabre S, Kleiner G, Polanco J, Khan Z, Alburquerque B, van de Guchte A, Dutta J, Francoeur N, Melo BS, Oussenko I, Deikus G, Soto J, Sridhar SH, Wang Y-C, Twyman K, Kasarskis A, Altman DR, Smith M, Sebra R, Aberg J, Krammer F, García-Sastre A, Luksza M, Patel G, Paniz-Mondolfi A, Gitman M, Sordillo EM, Simon V, van Bakel H. Introductions and early spread of SARS-CoV-2 in the New York City area. Science, 2020, 369:297-301

26. Hernandez MM, Gonzalez-Reiche AS, Alshammary H, Fabre S, Khan Z, van De Guchte A, Obla A, Ellis E, Sullivan MJ, Tan J, Alburquerque B, Soto J, Wang C-Y, Sridhar SH, Wang Y-C, Smith M, Sebra R, Paniz-Mondolfi AE, Gitman MR, Nowak MD, Cordon-Cardo C, Luksza M, Krammer F, van Bakel H, Simon V, Sordillo EM. Molecular evidence of SARS-CoV-2 in New York before the first pandemic wave. Nat Commun, 2021, 12:3463 
27. Rambaut A, Holmes EC, O’Toole Á, Hill V, McCrone JT, Ruis C, du Plessis L, Pybus OG. A dynamic nomenclature proposal for SARS-CoV-2 lineages to assist genomic epidemiology. Nat Microbiol, 2020, 5:1403-7

28. O’Toole Á, Scher E, Underwood A, Jackson B, Hill V, McCrone JT, Ruis C, Abu-Dahab K, Taylor

29. Katoh K, Misawa K, Kuma K-I, Miyata T. MAFFT: a novel method for rapid multiple sequence assignment in an emerging pandemic as an epidemiological tool. Github, n.d.

30. Hu T, Li J, Zhou H, Li C, Holmes EC, Shi W. Bioinformatics resources for SARS-CoV-2

32. Sanders RW, de Jong MD. Pandemic moves and countermoves: vaccines and viral variants. Lancet,

474 33. Caniels TG, Bontjer I, van der Straten K, Poniman M, Burger JA, Appelman B, Lavell AHA, discovery and surveillance. Brief Bioinform, 2021, 22:631-41

31. Hernandez (AceM1188) MM. AceM1188/SACOV_primer-probe_analyses. Zenodo, 2021. https://10.5281/zenodo.4920818. (accessed June 9, 2021) 2021, 397:1326-7 
medRxiv preprint doi: https://doi.org/10.1101/2021.09.09.21263348; this version posted September 16, 2021. The copyright holder for this preprint (which was not certified by peer review) is the author/funder, who has granted medRxiv a license to display the preprint in perpetuity.

It is made available under a CC-BY-ND 4.0 International license .

34. Volz E, Mishra S, Chand M, Barrett JC, Johnson R, Geidelberg L, Hinsley WR, Laydon DJ, Dabrera G, O’Toole Á, Amato R, Ragonnet-Cronin M, Harrison I, Jackson B, Ariani CV, Boyd O, Loman NJ, McCrone JT, Gonçalves S, Jorgensen D, Myers R, Hill V, Jackson DK, Gaythorpe K, Groves N, Sillitoe J, Kwiatkowski DP, Flaxman S, Ratmann O, Bhatt S, Hopkins S, Gandy A, Rambaut A, Ferguson NM, The COVID-19 Genomics UK (COG-UK) consortium. Transmission of SARS-CoV-2 Lineage B.1.1.7 in England: Insights from linking epidemiological and genetic data. BioRxiv, 2021. https://doi.org/10.1101/2020.12.30.20249034

35. Davies NG, Abbott S, Barnard RC, Jarvis CI, Kucharski AJ, Munday JD, Pearson CAB, Russell TW, Tully DC, Washburne AD, Wenseleers T, Gimma A, Waites W, Wong KLM, van Zandvoort K, Silverman JD, CMMID COVID-19 Working Group, COVID-19 Genomics UK (COG-UK) Consortium, Diaz-Ordaz K, Keogh R, Eggo RM, Funk S, Jit M, Atkins KE, Edmunds WJ. Estimated transmissibility and impact of SARS-CoV-2 lineage B.1.1.7 in England. Science, 2021, 372

36. Kupferschmidt K. Danish scientists see tough times ahead as variant rises. Science, 2021, 371:54950

37. Kemp SA, Meng B, Ferriera IA, Datir R, Harvey WT, Papa G, Lytras S, Collier DA, Mohamed A, Gallo G, Thakur N, The COVID-19 Genomics UK (COG-UK) Consortium, Carabelli AM, Kenyon JC, Lever AM, De Marco A, Saliba C, Culap K, Cameroni E, Piccoli L, Corti D, James LC, Bailey D, Robertson DL, Gupta RK. Recurrent emergence and transmission of a SARS-CoV-2 spike deletion H69/V70. BioRxiv, 2021:2020.12.14.422555

38. Public Health England. PHE investigating a novel variant of COVID-19, 2020

39. Galloway SE, Paul P, MacCannell DR, Johansson MA, Brooks JT, MacNeil A, Slayton RB, Tong S, Silk BJ, Armstrong GL, Biggerstaff M, Dugan VG. Emergence of SARS-CoV-2 B.1.1.7 Lineage 
medRxiv preprint doi: https://doi.org/10.1101/2021.09.09.21263348; this version posted September 16, 2021. The copyright holder for this preprint (which was not certified by peer review) is the author/funder, who has granted medRxiv a license to display the preprint in perpetuity.

It is made available under a CC-BY-ND 4.0 International license .

- United States, December 29, 2020-January 12, 2021. MMWR Morb Mortal Wkly Rep, 2021, 70:95-9

40. Firestone MJ, Lorentz AJ, Wang X, Como-Sabetti K, Vetter S, Smith K, Holzbauer S, Meyer S, Ehresmann K, Danila R, Lynfield R. First Identified Cases of SARS-CoV-2 Variant B.1.1.7 in Minnesota - December 2020-January 2021. MMWR Morb Mortal Wkly Rep, 2021, 70:278-9

41. Paul P, France AM, Aoki Y, Batra D, Biggerstaff M, Dugan V, Galloway S, Hall AJ, Johansson MA, Kondor RJ, Halpin AL, Lee B, Lee JS, Limbago B, MacNeil A, MacCannell D, Paden CR, Queen K, Reese HE, Retchless AC, Slayton RB, Steele M, Tong S, Walters MS, Wentworth DE, Silk BJ. Genomic Surveillance for SARS-CoV-2 Variants Circulating in the United States, December 2020-May 2021. MMWR Morb Mortal Wkly Rep, 2021, 70:846-50

42. Methods for the detection and identification of SARS-CoV-2 variants, 2021. https://www.ecdc.europa.eu/en/publications-data/methods-detection-and-identification-sars-cov-2variants. (accessed June 23, 2021)

43. Braybrook E, Pandey S, Vryonis E, Anderson NR, Young L, Grammatopoulos D. Screening for the alpha variant of SARS-CoV-2 (B.1.1.7) and the impact of this variant on circulating biomarkers in hospitalised patients. BioRxiv, 2021. https://doi.org/10.1101/2021.06.18.21258699

44. Centers for Disease Control and Prevention, US Department of Health and Human Services. CDC COVID Data Tracker, n.d. https://covid.cdc.gov/covid-data-tracker/\#variant-proportions. (accessed July 4, 2021)

45. Coronavirus Disease (COVID-19): Weekly Epidemiological Update (29 June 2021) - World, n.d. https://reliefweb.int/report/world/coronavirus-disease-covid-19-weekly-epidemiological-update-29june-2021. (accessed July 4, 2021) 
medRxiv preprint doi: https://doi.org/10.1101/2021.09.09.21263348; this version posted September 16, 2021. The copyright holder for this preprint (which was not certified by peer review) is the author/funder, who has granted medRxiv a license to display the preprint in perpetuity.

It is made available under a CC-BY-ND 4.0 International license .

526 46. New York City Department of Health. COVID-19: Data. NYC Health COVID-19: Data on

527 Variants, n.d. https://www1.nyc.gov/site/doh/covid/covid-19-data-variants.page. (accessed July 4, $528 \quad 2021)$

529 47. The Delta Variant: What Scientists Know. The New York Times, 2021.

530 https://www.nytimes.com/2021/06/22/health/delta-variant-covid.html. (accessed July 4, 2021)

531 48. WHO EMRO Weekly Epidemiological Monitor: Volume 14; Issue no 19; 9 May 2021, n.d.

532 https://reliefweb.int/report/afghanistan/who-emro-weekly-epidemiological-monitor-volume-14-

533 issue-no-19-9-may-2021. (accessed July 4, 2021)

534 49. GISAID - hCov19 Variants. Tracking of Variants, n.d. https://www.gisaid.org/hcov19-variants/.

$535 \quad$ (accessed July 4, 2021)

536 50. mjsull. mjsull/COVID_pipe: initial release (Version v0.1.0). Zenodo, 2020, April 29.

537 http://doi.org/10.5281/zenodo.3775031

538 
medRxiv preprint doi: https://doi.org/10.1101/2021.09.09.21263348; this version posted September 16, 2021. The copyright holder for this preprint (which was not certified by peer review) is the author/funder, who has granted medRxiv a license to display the preprint in perpetuity.

It is made available under a CC-BY-ND 4.0 International license .

\section{Acknowledgments}

We thank the members of MSHS CML, Simon, and van Bakel laboratories for providing any assistance when needed throughout this study. We are grateful for the continuous expert guidance provided by the ISMMS Program for the Protection of Human Subjects (PPHS).

The Research reported in this paper was supported by the National Institutes of Health (NIH) contract number HHSN272201400008C, the NIH Office of Research Infrastructure under award numbers S10OD018522 and S10OD026880, institutional and philanthropic funds (Open Philanthropy Project, \#2020-215611), as well as a Robin Chemers Neustein Postdoctoral Fellowship Award (to Dr. GonzalezReiche).

\section{Author contributions}

M.M.H., R.B., P.S., H.A., S.F., A.A., A.E.PM., M.R.G., M.D.N., and E.M.S. provided clinical samples for the study. M.M.H., R.B., P.S., L.C., F.C., H.S., and A.E.PM. accessioned clinical samples. A.S.GR., A.v.d.G., Z.K., B.A., and H.v.B. performed NGS experiments. R.S. provided NGS services. A.S.GR., and A.O. performed genome assembly, data curation and genotyping. M.M.H, L.H.P, and J.D.R. performed alignments and mismatch analyses. M.M.H., R.B., L.H.P, J.D.R., M.R.G., M.D.N., C.C.C., T.E.S., V.S., H.v.B., E.M.S., and A.E.PM analyzed, interpreted, or discussed data. M.M.H., E.M.S., and A.E.PM. wrote the manuscript. M.M.H., E.M.S., and A.E.PM. conceived the study. E.M.S. and A.E.PM. supervised the study. H.v.B., V.S., and E.M.S. raised financial support.

M.M.H. and A.E.PM are the guarantors of this work and, as such, had full access to all of the data in the study and take responsibility for the integrity of the data and the accuracy of the data analysis. 
medRxiv preprint doi: https://doi.org/10.1101/2021.09.09.21263348; this version posted September 16, 2021. The copyright holder for this preprint (which was not certified by peer review) is the author/funder, who has granted medRxiv a license to display the preprint in perpetuity. It is made available under a CC-BY-ND 4.0 International license.

\section{Competing Interests}

563 Robert Sebra is VP of Technology Development and a stockholder at Sema4, a Mount Sinai Venture.

564 This work, however, was conducted solely at Icahn School of Medicine at Mount Sinai. Otherwise, the 565 authors declare no competing interests. 


\section{Figure Legends}

569 Figure 1. Agena target detection rate in SARS-CoV-2-positive specimens by week. Heatmap

570 depicting the proportion of sequenced SARS-CoV-2-positive specimens that have detectable N1, N2,

571 N3, ORF1A, or ORF1AB targets by week from December 1, 2020 through April 24, 2021. International, 572 national, and global statistics are indicated by dates in purple font. NYC statistics are indicated by dates

573 in red font. Data for epidemiologic events obtained from ${ }^{38,39,41,44,46}$. The number of sequenced SARS-

574 CoV-2-positive specimens per week is indicated above each week (column). 
575 Figure 2. Impact of SARS-CoV-2 primer/probe binding site mismatches on Agena target detection

576 results. Number of mismatches normalized to the number of nucleotides in primer/probe binding sites

577 (PBS length) across five Agena MassARRAY ${ }^{\circledR}$ diagnostic targets: A: N1, B: N2, C: N3, D: ORF1A, E:

578 ORF1AB. Each point represents the calculated mismatches per specimen consensus genome for each

579 target PBS. Violin plots represent the distribution as density of the points grouped by primer/probe

580 sequence (forward (For), reverse (Rev), Probe) and by target detection result (detected (magenta),

581 dropout (turquoise)). The number of genome sequences analyzed for mismatches are depicted above

582 each violin plot. Medians are depicted as yellow lines. Bars above distributions reflect statistical

583 comparison of underlying distributions by Mann-Whitney test. Asterisks reflect $\mathrm{p}$-values $\left(^{*}, \mathrm{p}<0.05\right.$;

$584 * * * *, \mathrm{p}<0.0001)$ 
586 Figure 3. SARS-CoV-2 positional mismatches at target primer/probe binding sites. Line graphs

587 depict the percentage of specimen genomes with mismatches at individual basepair positions across

588 Agena MassARRAY ${ }^{\circledR}$ target PBSs: A: N1, B: N2, C: N3, D: ORF1A. There are three plots for each

589 target that correspond with the forward (For), reverse (Rev), and Probe binding sites. Two line plots are

590 depicted for each binding site to depict mismatches in genomes from specimens that yielded a detected

591 target result (magenta) or target dropout (turquoise). The percentage represents the number of genomes

592 with mismatches at each position relative to the number of genome sequences detected or not detected

593 by each target (annotated in each graph). 
596 Figure 4. Lineage-specific substitution interferes with SARS-CoV-2 diagnostic target detection. A:

597 Alignment of B.1.1.7 genomes associated with N3 target dropout. View is magnified to display

598 mismatches across the N3 forward (For) primer binding site. Sixty-four specimen genomes are indicated

599 by laboratory identifiers (Genome ID) and mismatches to the Wuhan-Hu-1 reference sequence

600 (NC_045512.2) and the N3 For primer (orange) are highlighted in green. Substitutions that correspond

601 with each of the mismatches are annotated below each panel. The lineage specific A28095T substitution 602 that is associated with N3 target dropout is highlighted in red with white typeface font. B: Alignment of 603 B.1.1.7 genomes associated with N3 target detection. Sixty-three individual genomes are indicated by 604 laboratory identifiers and mismatches are highlighted and annotated as in A. Note for substitutions that 605 are shared across both target results (e.g., dropout and detected), annotations are in boldface font. 

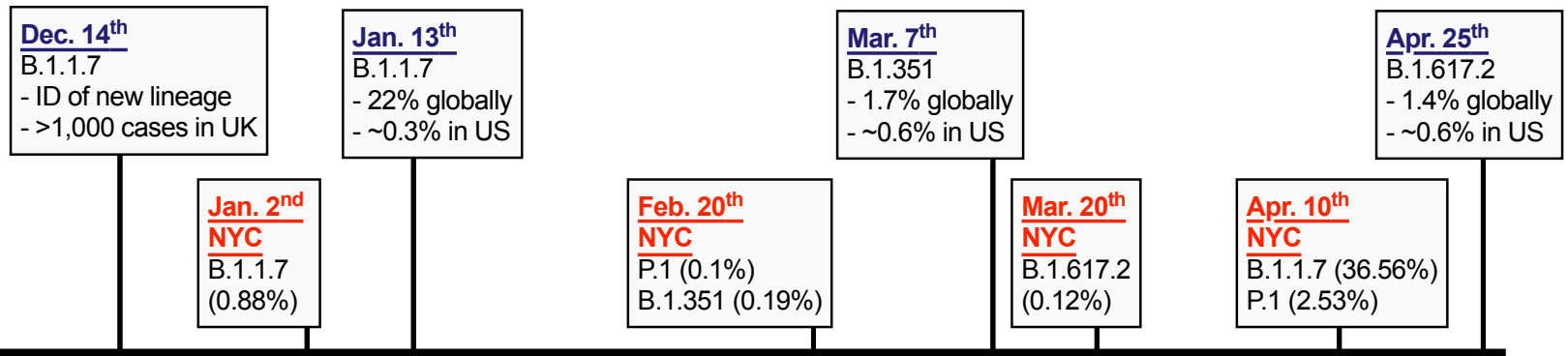

Target detection rate in SARS-CoV-2-positive specimens

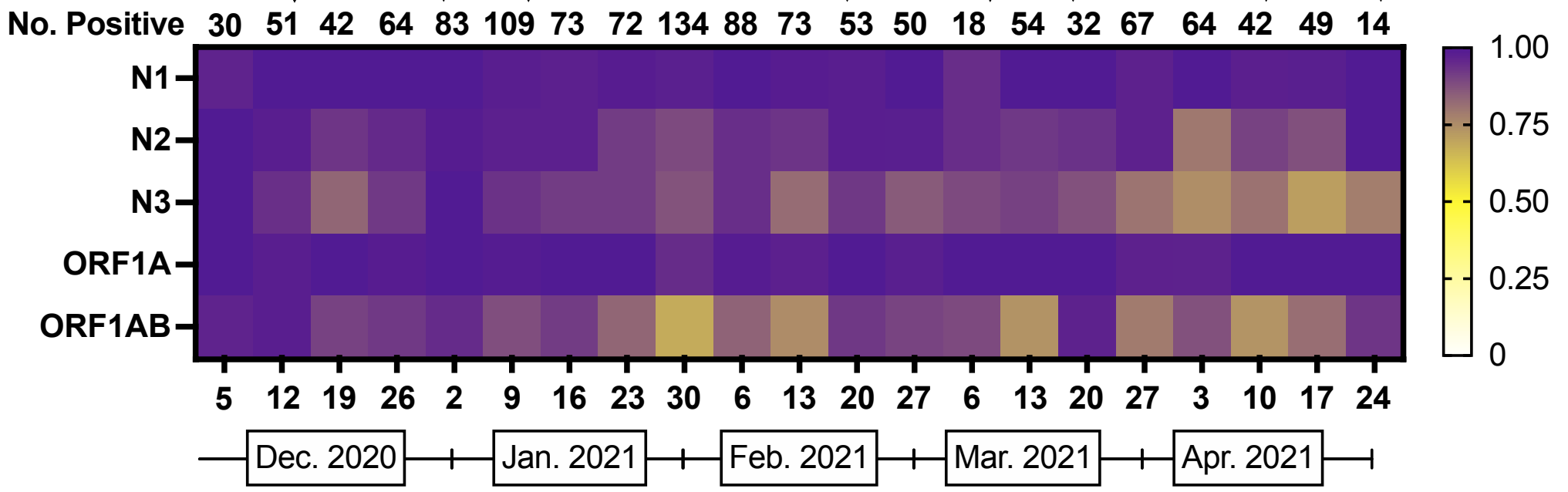

Week Ending 
A

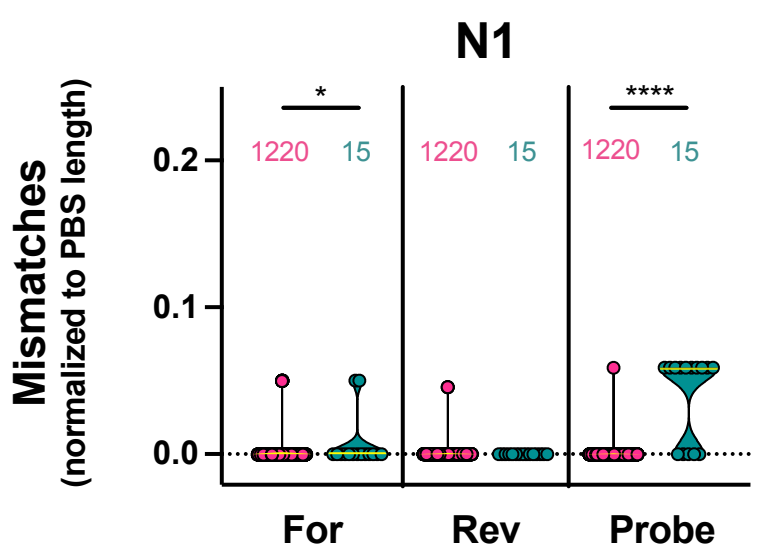

C

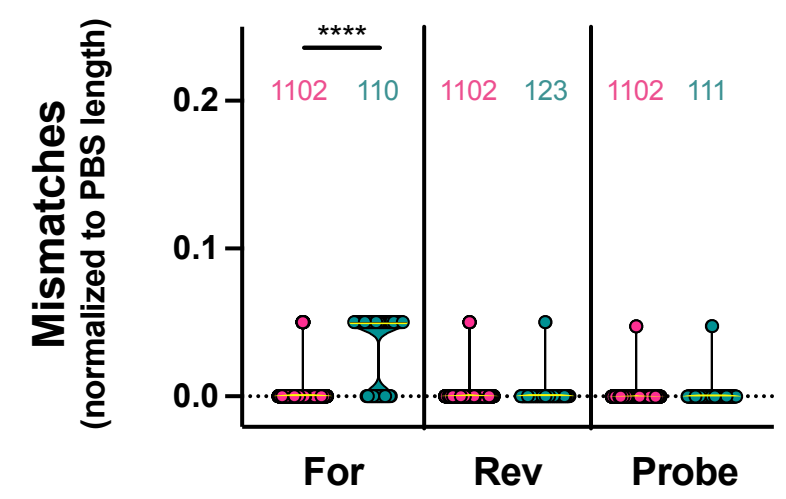

$\mathbf{E}$

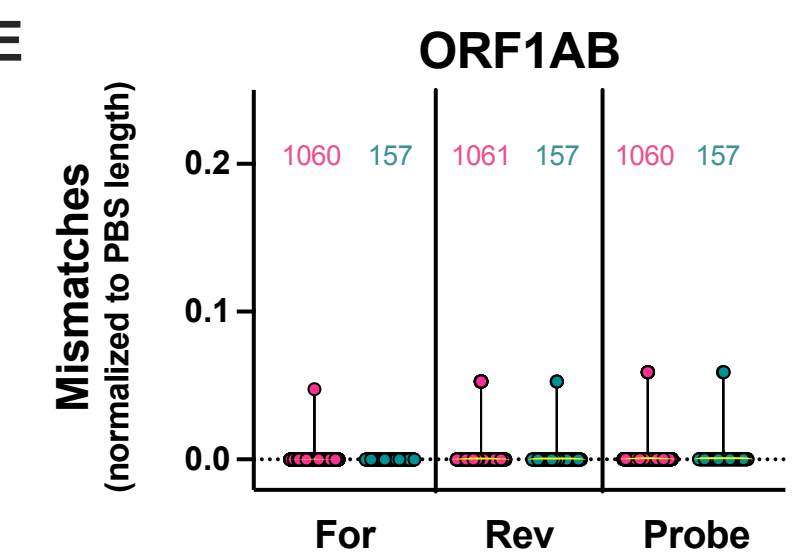

B

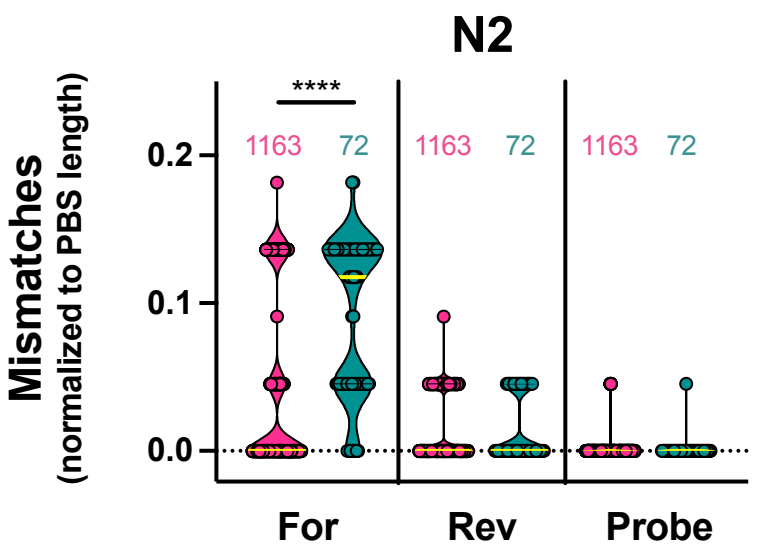

D

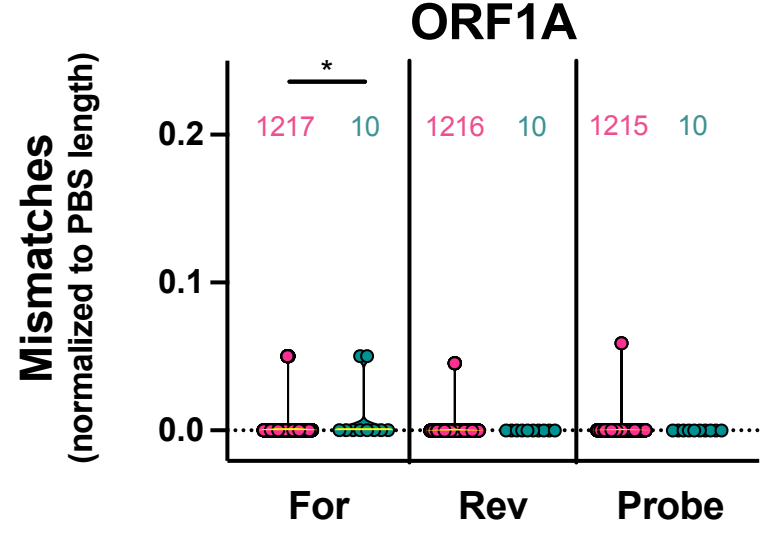

\begin{tabular}{l}
$\square$ Detected \\
$\square$ Dropout \\
\hline
\end{tabular}


A

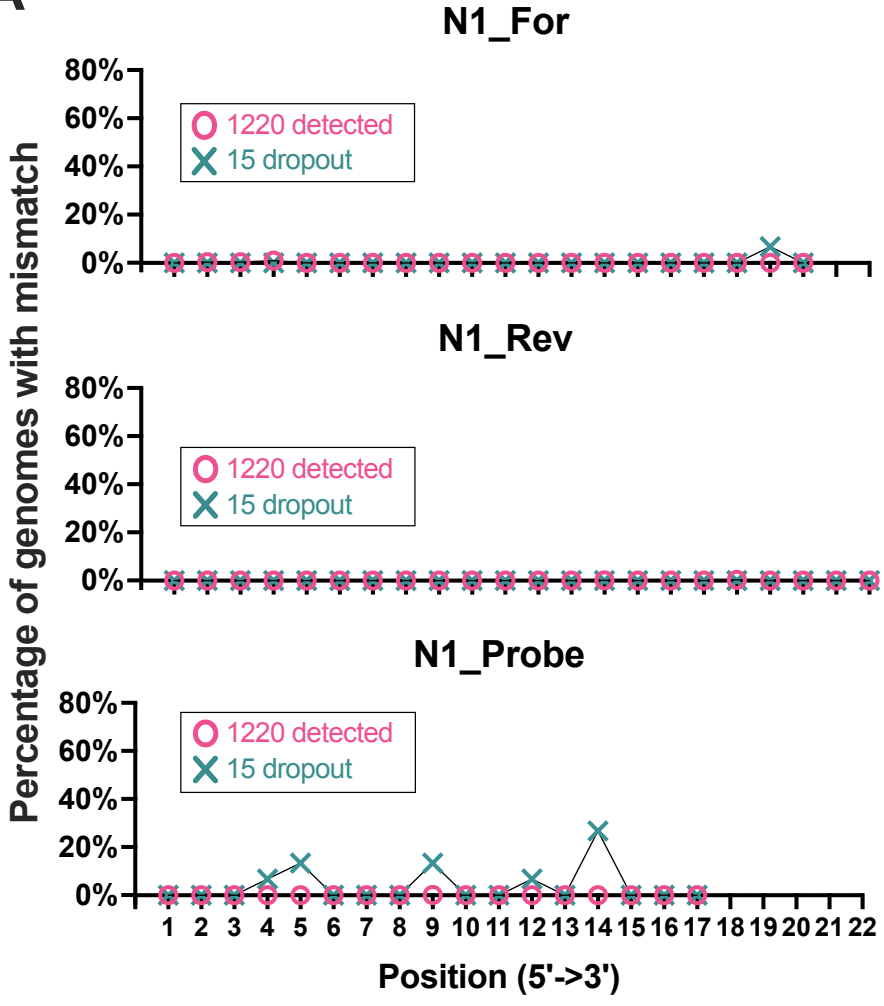

C

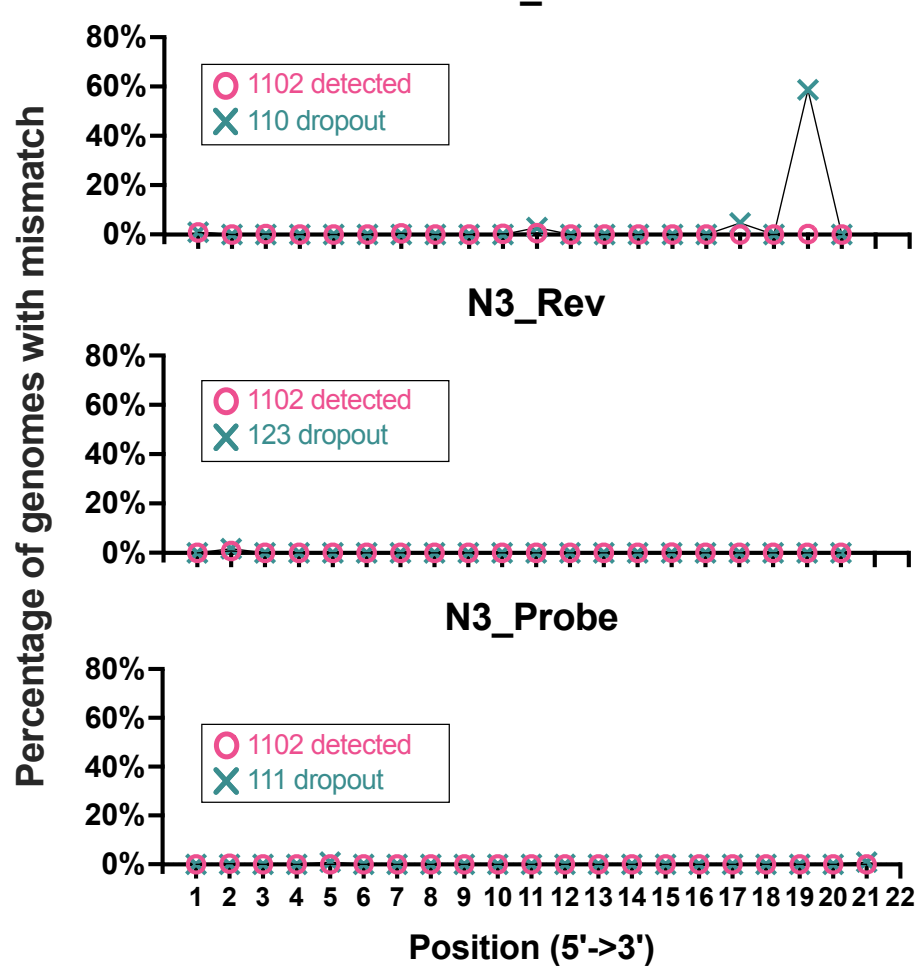

B
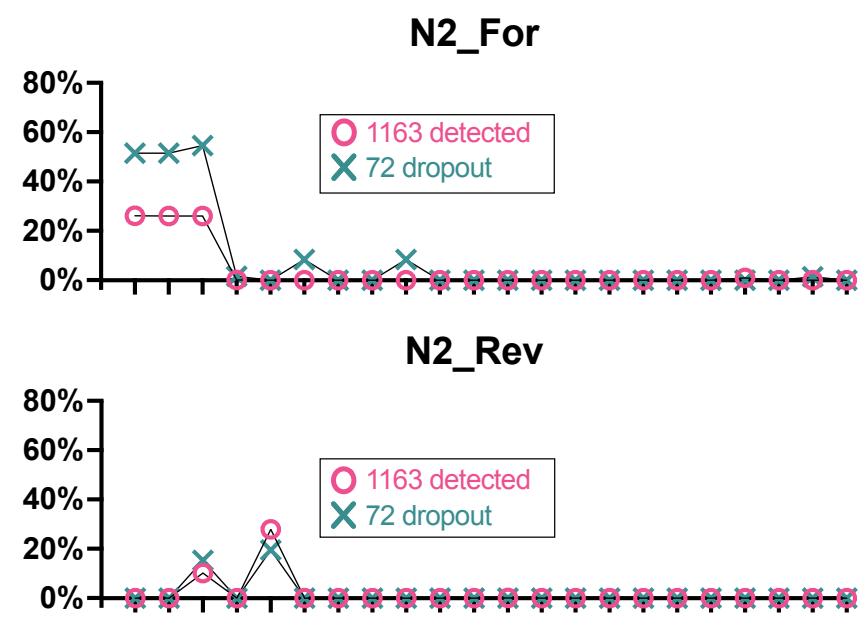

N2_Probe

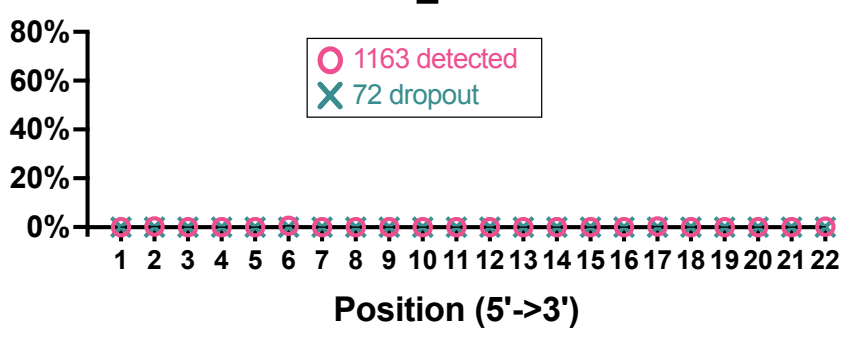

ORF1A_For

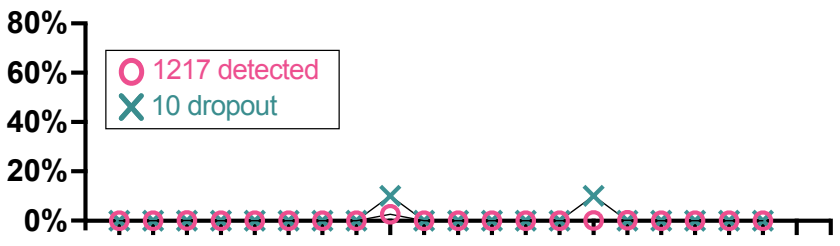

ORF1A_Rev
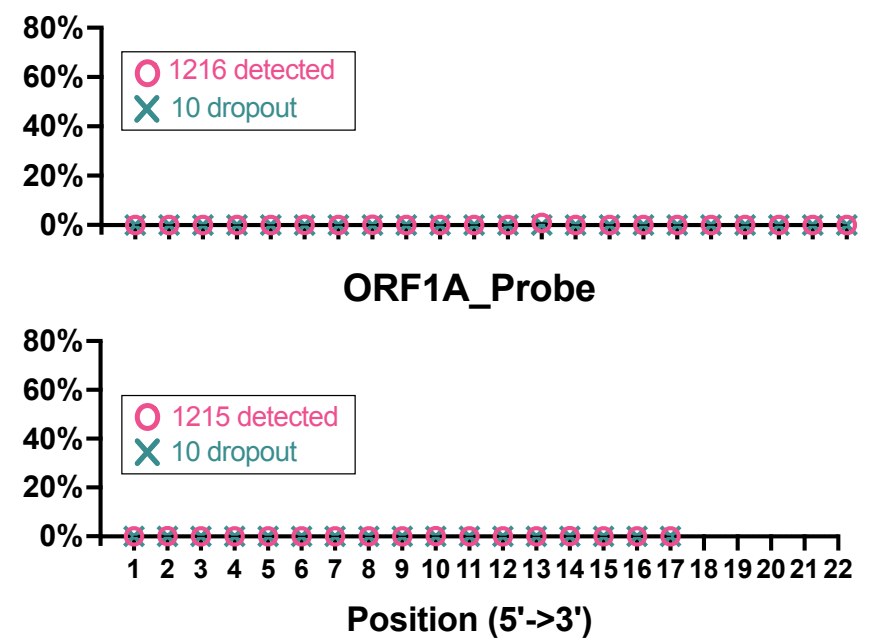
Figure 4

A Genome ID

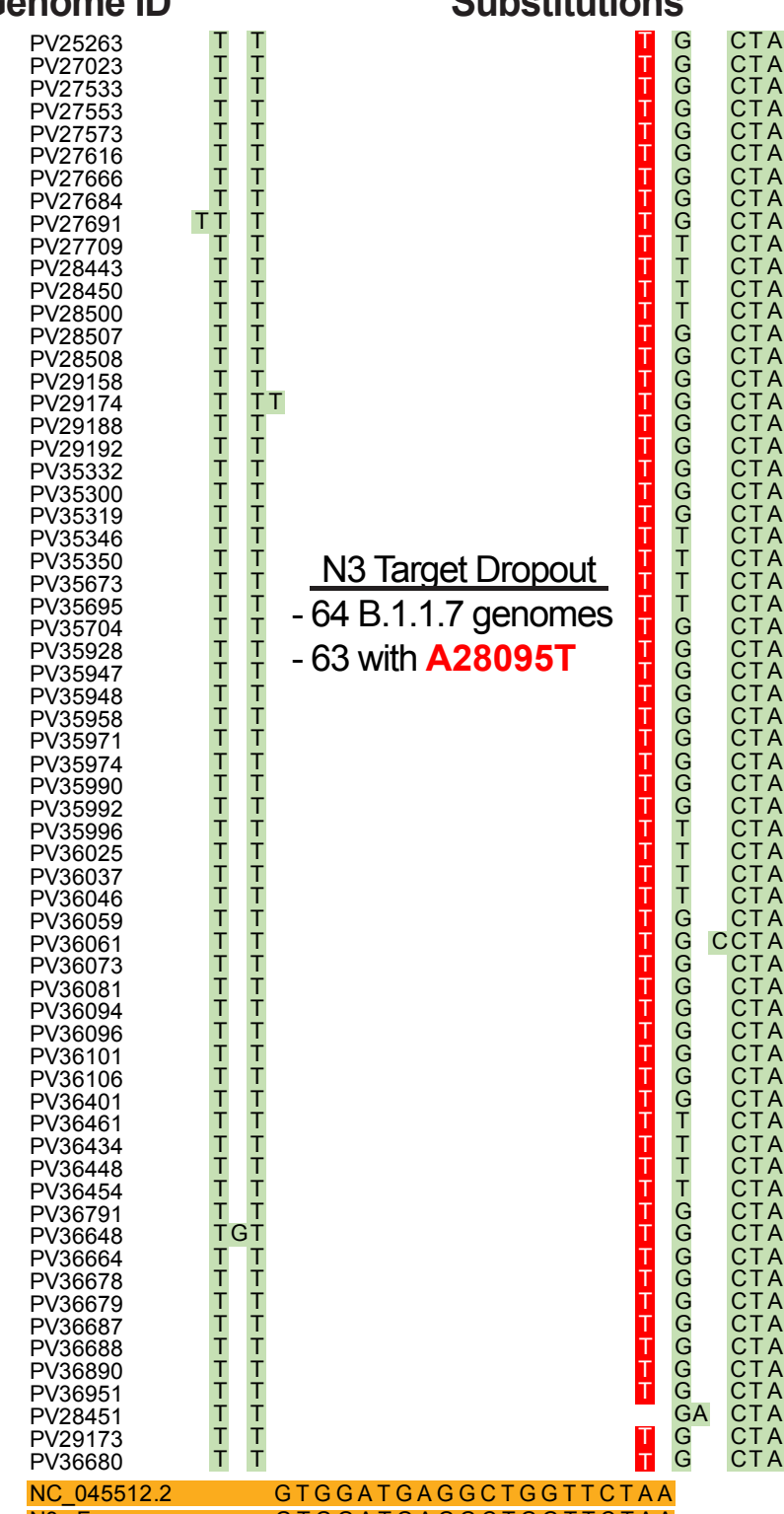

NC_045512.2 GTGGATGAGGCTGGTTCTAA ORF8
B

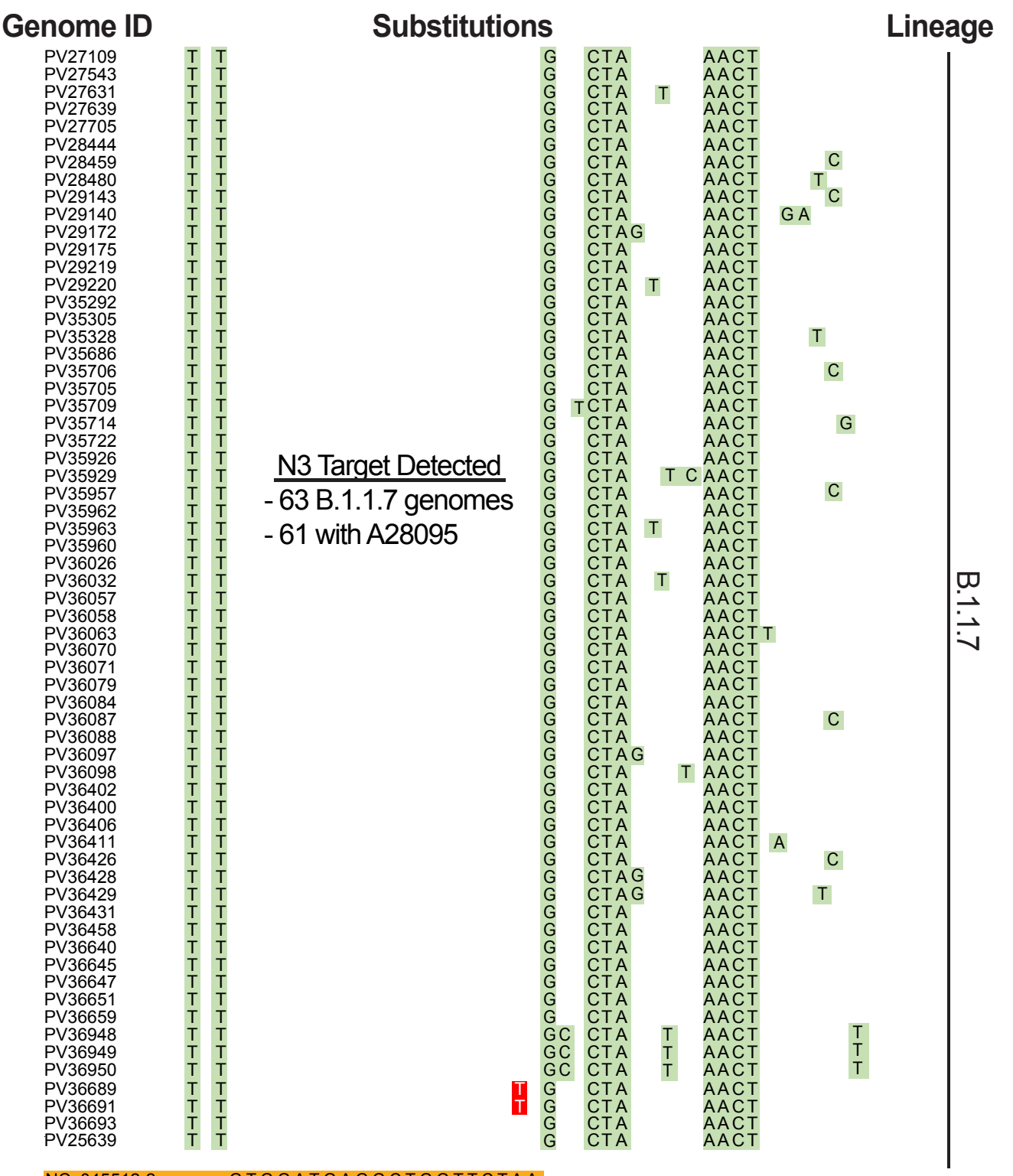

$\overline{\mathrm{C} 27960 \mathrm{~T}}$ C27972T G28048T G28075T 